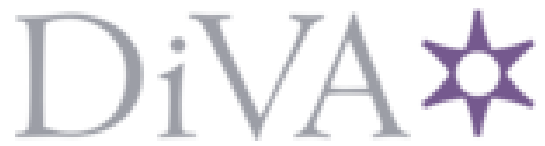

http://www.diva-portal.org

Preprint

This is the submitted version of a paper presented at IEEE Conference on Innovative Smart Grid Technologies.

Citation for the original published paper:

Hasanpor Divshali, P., Söder, L. (2017)

Improvement of RES hosting capacity using a central energy storage system

In: 2017 IEEE PES Innovative Smart Grid Technologies Conference Europe (ISGT-

Europe) (pp. 1-6).

https://doi.org/10.1109/ISGTEurope.2017.8260102

N.B. When citing this work, cite the original published paper.

Permanent link to this version:

http://urn.kb.se/resolve?urn=urn:nbn:se:kth:diva-222226 


\title{
Improvement of RES Hosting Capacity Using a Central Energy Storage System
}

\author{
P. Hasanpor Divshali and L. Söder \\ Department of Electrical Power and Energy Systems \\ KTH Royal Institute of Technology \\ Stockholm 10044, Sweden \\ poriahd@kth.se and lsod@kth.se
}

\begin{abstract}
High penetration of renewable energy sources (RESs) in distribution systems leads to reverse active power and voltage rise in low voltage (LV) grids, which limits the hosting capacity. Energy storage systems (ESSs) have been used to improve the hosting capacity by decreasing the reverse active power in some literature. ESSs can still improve the hosting capacity more by providing reactive power. The reactive power shows a little effect in existing researches, because they have mostly simulate LV grids without modeling transformers. However, the high reactance of the transformer magnifies the effectiveness of the reactive power control even more than the active power in some buses. This paper develops an optimal method for placement, sizing, and active and reactive power control of a central ESS to improve the hosting capacity. The simulation results in highly RES penetrated grids at Germany show the effectiveness of the proposed method.
\end{abstract}

Index Terms - Distribution grids, energy storage system, hosting capacity, reactive power control, renewable energy sources.

\section{INTRODUCTION}

Following the decision of the European Union to reduce the production of greenhouse gas emissions, European countries aimed to increase the penetration level of renewable energy sources (RESs) in their electricity power grids, e.g. Germany targeted to reach $38.6 \%$ penetration level of RESs in its electricity grid by 2020 [1]. A large portion of these RESs has been installed in the low voltage (LV) and medium voltage (MV) grids (e.g. 70\% for Germany [2]) and might create high reverse active power even more than the maximum demand.

This high reverse active power causes a considerable voltage rise in customer sides [3], which can violate the standard voltage restriction (e.g. $90 \%$ to $110 \%$ by EN 50160 [4]). This constrain limits the maximum amount of RESs, which can be installed in LV and MV grids, called hosting capacity. In order to handle this overvoltage and improve the hosting capacity, different methods have been used in literature such as 1) grid reinforcement [5], 2) on-load tap changers for $\mathrm{MV} / \mathrm{LV}$ transformers [6], 3) active power curtailment of RESs [7, 8], 4) demand side management [9, $10], 5)$ reactive power control by RES inverters [11-14], and 6) energy storage systems (ESSs) [15-21].

The first and second approaches are so expensive that are not practical for most cases. The third solution leads to lose a large part of production, particularly in case of photovoltaic (PV) plants, which have almost similar pattern every day. The fourth approach requires a two way communication and computational resource to handle uncertainty of RESs and it may be appropriate for the next generation of distribution grids. Although the reactive power control by RES inverters (fifth method) is a very effective method, it requires changing the invertor of all existing RESs connected to the distribution grid. The implementation of this approach also needs new regulation to incentivize the customer to participate the voltage control.

The cost of ESSs is steadily decreasing and electrical vehicle can be used as storage device in vehicle to grid mode $[22,23]$. As a result, many researchers consider storage system as a practical solution for improving the voltage regulation and the hosting capacity of distribution grids in the near future.

Generally, there are two arrangements for using ESSs in distribution grids: an individual ESS for each PV plant and one central ESS for the whole LV grid. Most of literature assumes that all PV plants have an individual ESS. In order to reduce reverse active power, [15] proposes that each ESS has a trapezoidal-shape output active power proportional to the local injected power. A method to flatten a net active power profile of each customer and mitigate voltage rise is presented in [16] using an individual ESS for each PV. This paper also simulates local control, centralized, and distributed control methods and discusses a bit about their advantages and disadvantages. Two similar methods to regulate voltage using a consensus technique, which is a common distributed control technique are proposed in $[17,18]$. Installing ESSs at all PVs 
is used to mitigate the neutral voltage rise (power balancing) in [19]. Although, having distributed ESSs in all PV plants technically is an effective solution, motivating all customers to install ESS needs to change the incentive regulation, in particular for existing PV owners.

For this reason, some other literatures work on a central ESS due to the fact that this idea is more likely to implement. A dynamic behavior of a central ESS for a small LV grid is studied in [24]. A central ESS, which is connected to all PVs by a DC link is used to mitigate the neutral voltage rise in [20]. A simplified method for placement and sizing of a central ESS to regulate voltage and minimize the cost is proposed in [21] based on a Fourier series based approach optimization method.

All above mention researches, which are working in a central ESS, neglect the influence of reactive power due to the high $\mathrm{R} / \mathrm{X}$ ratio of $\mathrm{LV}$ lines. However, since the voltage of the begging of $\mathrm{MV}$ feeder in distribution power system is almost fixed, the effective $\mathrm{R} / \mathrm{X}$ ratio in voltage regulation includes MV lines, MV/LV transformers, and LV lines. $\mathrm{MV} / \mathrm{LV}$ transformers have a large inductive impedance and therefore, this cumulative $\mathrm{R} / \mathrm{X}$ ratio of distribution system (from beginning of the MV feeder to the LV nodes) is around one, as shown in section III. This cumulative impedance makes the reactive power control almost as effective as the active control in practical distribution grids.

This research develops an optimal control for a central ESS in LV grids by determining the place, size, and the output active and reactive power. The proposed method is simulated in three LV grids in Germany as a part of a project called SNOOPI, Smart Network Control with Coordinated PV Infeed [25]. SNOOPI was defined to find the best solutions to install more PV plants in LV grids by regulating voltage. In the first stage of this project, two large MV feeders having about $80 \%$ RESs penetration based on yearly energy production with details of three LV grids were selected. Then, due to lack of measurement in distribution networks, the consumption and generation profiles were estimated and verified by using historical data and some measurements [26]. The proposed control method is tested in these LV grids using the actual production and consumption profile. Although, these LV grids have different specifications, the results of the proposed control method show the effectiveness of the optimal reactive power control for a central ESS in all investigated grids. In this paper, due to space limitation, only results for one LV grid are presented.

The rest of this paper is organized as follows: Section II presents the proposed optimal control method for a central ESS and details how to calculate the hosting capacity. Section III shortly describes the investigated LV grid. The results are shown in section IV and finally, section V concludes the paper.

\section{PROBLEM FORMULATION}

\section{A. Voltage Regulation}

In order to improve hosting capacity of distribution systems for RESs, the voltage rise should be mitigated. This subsection formulates the voltage regulation of a LV network as an objective function, which should be minimized to allow finding the optimal output of a central EES in a specific location. The objective function $(\Delta V)$ can be defined as:

$$
\begin{gathered}
\Delta V=\sum_{t=1}^{T}\left(\overline{\Delta V(t)}^{2}+\underline{\Delta V(t)^{2}}\right) . \\
\overline{\Delta V(t)}=\left\{\begin{array}{cc}
\max \left(v_{i}(t)\right)-V_{M} & \max \left(v_{i}(t)\right) \geq V_{M} \\
0 & \max \left(v_{i}(t)\right)<V_{M}
\end{array}, \quad \forall i,\right. \\
\underline{\Delta V(t)}=\left\{\begin{array}{cc}
V_{m}-\min \left(v_{i}(t)\right) & V_{m} \geq \min \left(v_{i}(t)\right) \\
0 & V_{m}<\min \left(v_{i}(t)\right)
\end{array}, \quad \forall i .\right.
\end{gathered}
$$

Where $t$ is the time interval; $v_{i}(t)$ is the voltage of $i$-th bus in time $t ; V_{m}$ and $V_{M}$ are respectively the minimum and maximum desirable voltage magnitude; and $T$ is the number of time intervals in each day. It is noteworthy to mention that selecting a narrow desirable range for voltage leads to more consumption of reactive power and more power loss. Here, $V_{m}$ is selected $0.95 \mathrm{pu}$ and $V_{M}$ equals to $1.05 \mathrm{pu}$.

The output active and reactive power of the central ESS changes the power flow of the distribution grid. Consequently, its output power could be controlled to minimize $\Delta V$ while the internal limitations of the ESS are satisfied.

\section{B. Energy Storage Model}

Different kinds of storage technologies can be used as a central storage system [27]. Here, a general battery storage system is used. A battery storage system includes a battery bank, which can store a limited amount of energy and a power converter part, which have a maximum output power is used. The amount of available energy in a battery bank is usually called 'state of charge' (SOC) and can be calculated as follows:

$$
\operatorname{SOC}(t+1)=\left\{\begin{array}{lc}
\operatorname{SOC}(t)+\eta P_{b}(t) & \text { Charging } \\
\operatorname{SOC}(t)-P_{b}(t) / \eta & \text { Discharging }
\end{array} .\right.
$$

Where $P_{b}(t)$ is the output active power of the battery in time $t$ and $\eta$ is the charging / discharging efficiency. In order to maximize the life time of a battery, its SOC should be kept between a maximum $\left(S O C_{M}\right)$ and minimum $\left(S O C_{m}\right)$ amount:

$$
\operatorname{SOC}_{m} \leq \operatorname{SOC}(t) \leq \operatorname{SOC}_{M} .
$$

Furthermore, the ESS should be ready for the next day, and therefore, the SOC of the battery bank in the end of the 


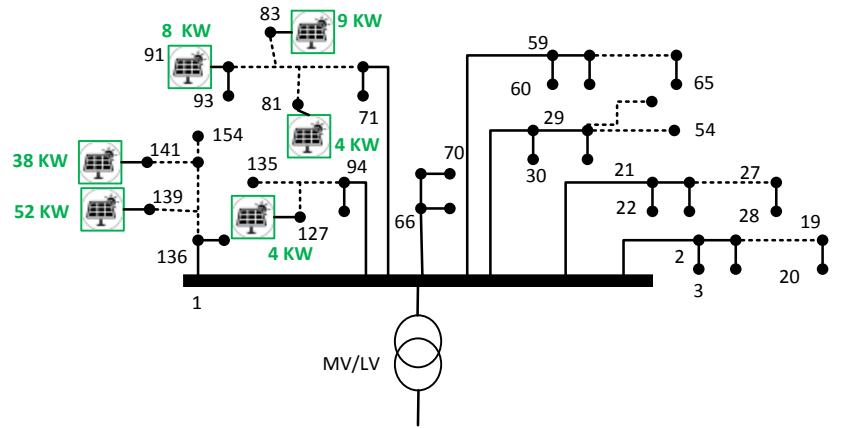

Fig. 1. Single line diagram of investigated LV grid

day (beginning of the next day) should be same as the initial SOC (beginning of the current day):

$$
\operatorname{SOC}(T)=\operatorname{SOC}(0) .
$$

The power converter also has some constraints, which ties the reactive power control to the active power control, as follows:

$$
\begin{aligned}
& P_{m} \leq P_{b}(t) \leq P_{M}, \\
& Q_{m} \leq Q_{b}(t) \leq Q_{M}, \\
& \sqrt{P_{b}(t)^{2}+Q_{b}(t)^{2}}<S_{M} .
\end{aligned}
$$

Where $Q_{b}(t)$ is the output reactive power of the converter; $P_{m}$ and $Q_{m}$ are respectively the maximum active and reactive power of discharging mode; $P_{M}$ and $Q_{M}$ are respectively the maximum active and reactive power of charging mode; and $S_{M}$ is the maximum converter apparent power.

\section{ESS optimum control method}

The output active and reactive power of the central battery storage system can be optimally selected by solving a nonlinear optimization problem (minimizing $\Delta V$ of (1)) subject to constraints of (4)-(7) and load flow equations as follows:

$$
\begin{aligned}
& \sum_{k=1}^{n}\left|V_{i}\right|\left|V_{k}\right|\left|Y_{i k}\right| \cos \left(\delta_{i}-\delta_{k}-\theta_{i k}\right)=P_{i n j, i}, \quad \forall i, \\
& \sum_{k=1}^{n}\left|V_{i}\right|\left|V_{k}\right|\left|Y_{i k}\right| \sin \left(\delta_{i}-\delta_{k}-\theta_{i k}\right)=Q_{i n j, i}, \quad \forall i .
\end{aligned}
$$

where $n$ is the number of bus in the grid, $\delta$ is the voltage angle; $\left|Y_{i k}\right|$ and $\theta_{i k}$ are respectively the magnitude and angle of the corresponding element of Y-bus matrix; $P_{i n j, i}$ and $Q_{i n j, i}$ are respectively the net injected active and reactive power of $i$-th bus. Therefore, in bus b, where the central ESS is connected, $P_{i n j, i}$ and $Q_{i n j, i}$ can be calculated as:

$$
\begin{aligned}
& P_{i n j, \mathrm{~b}}(t)=P_{g e n, b}(t)-P_{\text {Load }, \mathrm{b}}(t)+P_{b}(t), \\
& Q_{i n j, \mathrm{~b}}(t)=Q_{g e n, b}(t)-Q_{\text {Load }, b}(t)+Q_{b}(t) .
\end{aligned}
$$

where $P_{g e n, b}(t)$ and $Q_{g e n, b}(t)$ are the injected active and reactive power of bus $b$ at time $t$, and $P_{\text {Load, } b}(t)$ and $Q_{\text {Load, },}(t)$ are respectively the load active and reactive power of bus $b$ at time $t$.

In this nonlinear optimization problem, last term of (7) links the output reactive power at time $t$ to the output active power at the same time and constraints (4)-(6) link the output active power at time $t$ to the active power of other times. Consequently, this optimization problem has $2 * T$ design parameters in a given characteristic and place of an ESS to find the optimum output active and reactive power.

In this paper, the calculation is done for $T=24$ and time interval equals to one hour. As a result, the nonlinear optimization problem (objective function: (1)) has 48 design parameters (the output active and reactive power of the storage for each time interval), 48 lower and upper bounds (first two lines of (7)), 24 nonlinear inequality constraints (last line of (7)), and $2 n+1$ nonlinear equality constraints ((6) and (9)).

\section{Hosting Capacity improvment}

In this paper, in order to calculate the effect of a central ESS on improving the hosting capacity of LV networks, the following procedure is performed:

(1) Increase the RESs of the LV network until the maximum voltage of the critical day reach to $1.1 \mathrm{pu}$ (the maximum hosting capacity without ESS).

(2) Find the place and the output active and reactive power of the central ESS, which maximize the hosting capacity for a certain size of an ESS using the proposed method described in the previous subsections.

(3) Simulate the optimal ESS to improve the voltage regulation.

(4) Increase the RESs of the LV network with ESS more until the maximum voltage reach again 1,1 pu (the maximum hosting capacity using ESS)

(5) Calculate the ratio of hosting capacity in step 4 over the step 2, as the hosting capacity improvement

\section{NETWORKS SPECIFICATIONS}

In SNOOPI project, two radial MV feeders in Germany, with details of three LV networks have been investigated. However, only the results of the first LV grid are presented here. The first MV feeder has several small PV plants connected to LV grids and a 7.3 MW solar park directly connected to the MV feeder. The penetration level of RES in this feeder totally becomes $75 \%$ of the yearly energy consumption. The reverse active power in the beginning of this MV feeder reaches 7.2 MW, while its demand peak is 3.7 MW. The MV grid supplies about $40 \mathrm{MV} / \mathrm{LV}$ substations, which are simulated as an aggregated load and generation profiles except one. One of the substations is simulated with all LV details, as shown in Fig. 1. The LV network has 154 nodes including 79 junction and 75 consuming nodes; also it has $6 \mathrm{PV}$ plants with total install capacity of $115 \mathrm{~kW}$. The transformer is a $400 \mathrm{kVA}$ with $\mathrm{UK}=6 \%$ and no-load loss of 


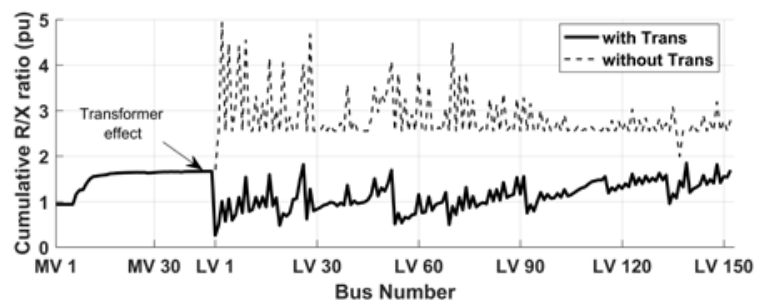

Fig. 2. The cumulative R/X ratio from the beginning of MV feeder to each bus
$4.8 \mathrm{~kW}[26]$.

The effectiveness of the voltage control by the reactive power in compare to the active power is largely dependent on the ratio of the resistance to reactance $(\mathrm{R} / \mathrm{X})$ in the network. In the MV feeders, the $\mathrm{R} / \mathrm{X}$ ratio of lines is in the range of 0.9 to 1.7 , while this value for the $\mathrm{LV}$ feeders is in the range of 2.6 to 8.2, in this network. On the other hand, the MV/LV transformers have large inductive impedance with $\mathrm{R} / \mathrm{X}$ ratio about 0.2 .

In many researches, since the MV feeder and transformer were not modeled, the $\mathrm{R} / \mathrm{X}$ ratio was obtained based on just $\mathrm{LV}$ lines. However, since in a distribution grid, the voltage in the beginning of the MV feeder is kept fixed by on-load tap changer, the voltage rise should be calculated from this point. Therefore, the cumulative $\mathrm{R} / \mathrm{X}$ ratio from the beginning of the MV feeder to the LV node, which has the central BSS, has effect on voltage regulation. This cumulative impedance includes MV lines, the large reactance of $\mathrm{MV} / \mathrm{LV}$ transformer, and LV lines in pu. The cumulative $\mathrm{R} / \mathrm{X}$ ratio of each bus in the simulated grid is shown in Fig. 2. This ratio demonstrates that in many buses the reactive power control can be even more effective than the active power control, in particular in buses located near the transformer.

\section{Simulation RESUlTS}

In order to demonstrate the influence of ESS on the hosting capacity improvement, first, as mention in section II.D, the maximum hosting capacity of LV grids without ESS is calculated. In this case, the RESs can be increased by $90 \%$ until the hourly average voltage of the critical buses in the critical day of 2015 (June 20-th) reaches 1.1 pu. Fig. 3 shows the voltage profile of $\mathrm{LV}$ grids in different hours, for the maximum hosting capacity without any ESS. As it is expected, the voltage in one LV feeder, which has two large PV plants, reaches to $1.1 \mathrm{pu}$ while other LV buses have lower voltage near the substation voltage.

By installing a central battery storage system in the best place (bus 141 in this LV grid) using the optimal control by the proposed method, the voltage rise can be mitigated and the hosting capacity be improved. Table I lists the improvement percentage in hosting capacity for different size of battery bank and converter size, when the ESS cannot supply the reactive power. In order to show effects of the reactive power control, the hosting capacity improvement for the same ESS having the ability of both active and reactive

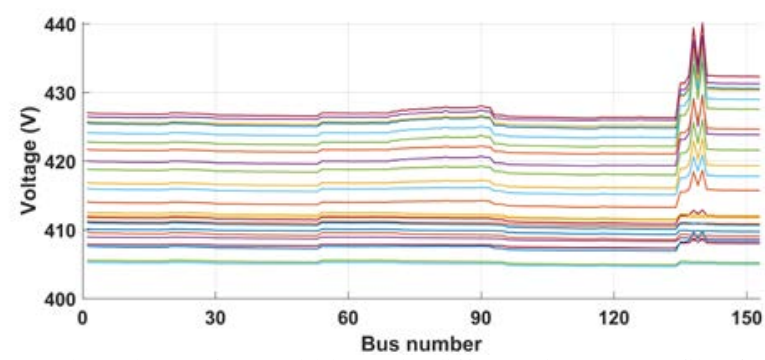

Fig. 3. The voltage of $\mathrm{LV}$ grid buses in different time ( 24 profiles for $\mathrm{t}=1$ to 24) in maximum hosting capacity without ESS

power control is listed in Table II. The comparison of these results shows that using both active and reactive power control improves the hosting capacity about three times. Table II also shows that a $20 \mathrm{kVA}$ increase in the converter size can improve hosting capacity about $7 \%$ while a $20 \mathrm{kWh}$ increase in the battery size can improve the hosting capacity only less than $1 \%$.

In order to compare the cost of ESS, five different cases, which can improve the hosting capacity about 50\% are selected as follows`:

- Case 1: $160 \mathrm{kVA}$ converter without battery (cost $49 \mathrm{k} €$ )

- Case 2: $140 \mathrm{kVA}$ converter, 20kWh battery (cost $62 \mathrm{k} €$ )

- Case 3: $140 \mathrm{kVA}$ converter, 40kWh battery (cost $82 \mathrm{k} €$ )

- Case 4: $140 \mathrm{kVA}$ converter, 60kWh battery (cost $102 \mathrm{k€}$ )

- Case 5: $140 \mathrm{kVA}$ converter, 80kWh battery (cost $122 \mathrm{k€}$ )

The costs are calculated based on the average cost of 1000 $€ / \mathrm{kWh}$ for a Li-Ion battery and $350 € / \mathrm{kVA}$ for a power converter [27]. Fig. 4 shows the optimal output of the central ESS for these cases. The maximum and minimum voltages of the LV grid during time in different cases are respectively

TABLE I. THE OPTIMAL HOSTING CAPACITY IMPROVEMENT (\%) BY A CENTRAL ESS WITHOUT REACTIVE POWER CONTROL

\begin{tabular}{|c|ccccc|}
\cline { 2 - 6 } \multicolumn{1}{c|}{} & \multicolumn{5}{c|}{ SOC $_{\mathbf{M}}(\mathbf{k W h})$} \\
\hline $\mathrm{S}_{\mathbf{M}}$ (kVA) & $\mathbf{0}$ & $\mathbf{2 0}$ & $\mathbf{4 0}$ & $\mathbf{6 0}$ & $\mathbf{8 0}$ \\
\hline $\mathbf{2 0}$ & - & 3.78 & 8.13 & 8.78 & 8.84 \\
$\mathbf{4 0}$ & - & - & 8.36 & 9.06 & 10.2 \\
$\mathbf{6 0}$ & - & - & - & 9.45 & 12.1 \\
$\mathbf{8 0}$ & - & - & - & - & 12.8 \\
\hline
\end{tabular}

TABLE II. THE OPTIMAL HOSTING CAPACITY IMPROVEMENT (\%) BY A CENTRAL ESS USING REACTIVE POWER CONTROI

\begin{tabular}{|c|ccccc|}
\cline { 2 - 6 } \multicolumn{1}{c|}{} & \multicolumn{5}{c|}{ SOC $_{\mathbf{M}}(\mathbf{k W h})$} \\
\hline $\mathbf{S}_{\mathbf{M}} \mathbf{( k V A )}$ & $\mathbf{0}$ & $\mathbf{2 0}$ & $\mathbf{4 0}$ & $\mathbf{6 0}$ & $\mathbf{8 0}$ \\
\hline $\mathbf{2 0}$ & 8,20 & 9,50 & 9,94 & 10,22 & 10,40 \\
$\mathbf{4 0}$ & 14,69 & 16,78 & 17,36 & 18,64 & 18,24 \\
$\mathbf{6 0}$ & 21,54 & 24,40 & 25,07 & 25,64 & 26,16 \\
$\mathbf{8 0}$ & 28,75 & 32,12 & 33,19 & 33,81 & 34,39 \\
$\mathbf{1 0 0}$ & 36,34 & 40,25 & 41,77 & 42,44 & 43,06 \\
$\mathbf{1 2 0}$ & 44,36 & 48,62 & 50,61 & 51,59 & 52,26 \\
$\mathbf{1 4 0}$ & 52,81 & 57,48 & 59,83 & 61,29 & 62,05 \\
$\mathbf{1 6 0}$ & 61,74 & 66,85 & 69,62 & 71,41 & 72,48 \\
\hline
\end{tabular}




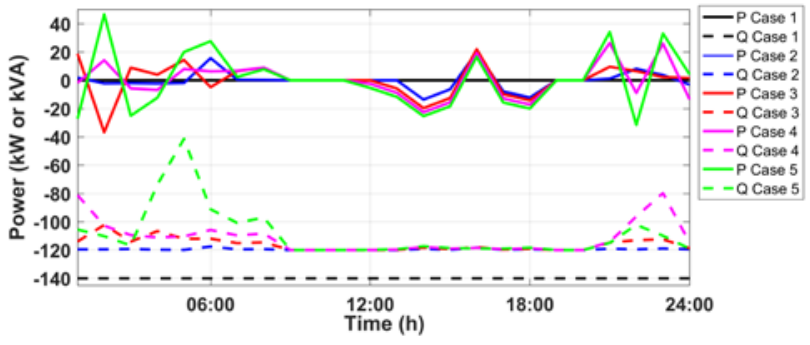

Fig. 4. The output active and reactive power in different cases

shown in Fig. 5 and 6. The maximum voltage in different cases has almost similar peak about $425 \mathrm{~V}$ (15 V less than the case without battery) and the minimum voltages stay in the desirable range.

The optimum reactive power during night has some fluctuations as shown in Fig. 4. These fluctuations happen because all voltages are in the desirable range in this time and therefore objective function remains zero and the optimization method cannot select a specific output reactive power. These fluctuations can be removed by defining zero output reactive power when all voltages are in the desirable range.

Since the optimal reactive power of the central ESS is always negative and also the case 1, without a battery bank, has the best outcome and least cost, a D-STATCOM or a SVC (switching reactor) might provide the same hosting capacity improvement even with less cost. However, reactive power control slightly increases the maximum current and energy loss. Using a SVC and designing a dynamic controller for improving the hosting capacity of LV grid is one of our future studies.

\section{CONCLUSION}

This paper investigates using a central energy storage system having active and reactive power control in order to improve hosting capacity of LV grids. The sizing, placement, and optimal control of active and reactive power are formulated as a multi-variable nonlinear constrained optimization problem. The simulation results in Germany LV grids show that the reactive power control of ESS could be even more effective than active power control due to the large impedance of MV/LV transformers and high cost of battery bank. In more details, the results illustrate that a DSTATCOM or even a controllable reactor can improve the hosting capacity of LV grids as much as a battery storage system with considerably lower cost. However, the battery storage system and active power control can slightly improve the overcurrent constraints while the reactive power control increases the current negligibly.

Using a central ESS or controllable reactive power still need more study in dynamic behavior, particularly in interaction with other voltage controllers, which is one of the authors' future research.

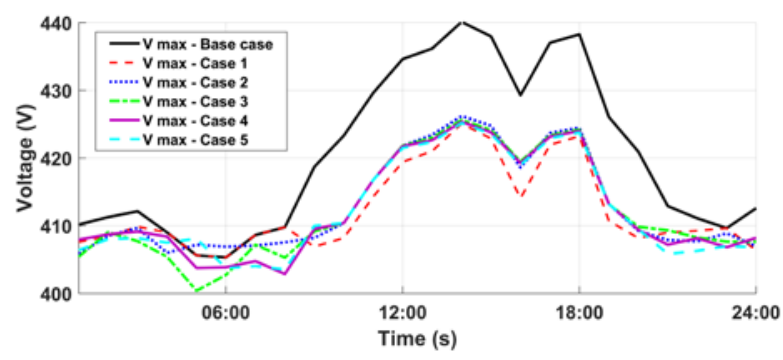

Fig. 5. The maximum voltage of the LV grid (critical bus voltage) during time

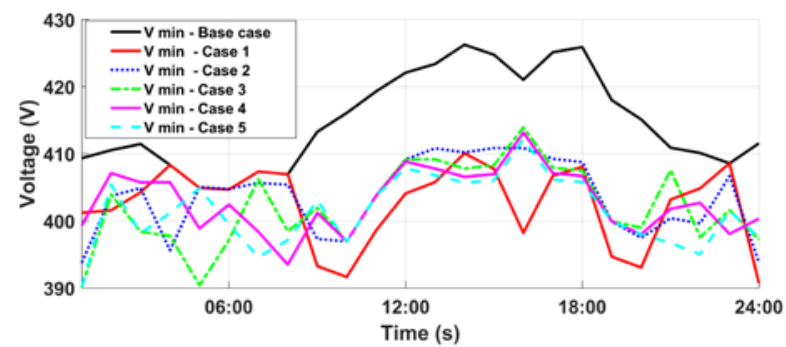

Fig. 6. The minimum voltage of the LV grid during time

\section{REFERENCES}

[1] "National Renewable Energy Action Plan in accordance with Directive 2009/28/EC on the promotion of the use of energy from renewable sources," Federal Republic of Germany, Germany2009, Available: http://ec.europa.eu/energy/node/71.

[2] A. Samadi, L. Söder, E. Shayesteh, and R. Eriksson, "Static equivalent of distribution grids with high penetration of pv systems," IEEE Trans. Smart Grid, vol. 6, no. 4, pp. 1763-1774, 2015.

[3] M. Brenna et al., "Automatic distributed voltage control algorithm in smart grids applications," IEEE Trans. Smart Grid, vol. 4, no. 2, , 2013.

[4] Voltage Disturbances Standard EN 50160, 2011.

[5] T. Stetz, F. Marten, and M. Braun, "Improved low voltage gridintegration of photovoltaic systems in Germany," IEEE Trans. Sustain. Energy, vol. 4, no. 2, pp. 534-542, 2013.

[6] R. Kabiri, D. G. Holmes, B. P. McGrath, and L. G. Meegahapola, "LV grid voltage regulation using transformer electronic tap changing, with PV inverter reactive power injection," IEEE Trans. Emerg. Sel. Topics Power Electron., vol. 3, no. 4, pp. 1182-1192, 2015.

[7] R. Tonkoski, L. A. Lopes, and T. H. El-Fouly, "Coordinated active power curtailment of grid connected PV inverters for overvoltage prevention," IEEE Trans. Sustain. Energy, vol. 2, pp. 139-147, 2011.

[8] S. Ghosh, S. Rahman, and M. Pipattanasomporn, "Distribution Voltage Regulation through Active Power Curtailment with PV Inverters and Solar Generation Forecasts," IEEE Trans. Sustain. Energy, Early access.

[9] E. Yao, P. Samadi, V. W. Wong, and R. Schober, "Residential demand side management under high penetration of rooftop photovoltaic units," IEEE Trans. Smart Grid, vol. 7, no. 3, pp. 1597-1608, 2016.

[10] P. Hasanpor. Divshali and B. J. Choi, "Indirect Real-Time EVs Charging Technique Based on an Imperfect Competition Market," presented at the IEEE SmartGridComm, Australia, 2016.

[11] A. Samadi, R. Eriksson, L. Söder, B. G. Rawn, and J. C. Boemer, "Coordinated active power-dependent voltage regulation in distribution grids with PV systems," IEEE Trans. Power Del., vol. 29, no. 3, 2014.

[12] A. Samadi, E. Shayesteh, R. Eriksson, B. Rawn, and L. Söder, "Multiobjective coordinated droop-based voltage regulation in distribution grids with PV systems," Renewable Energy, vol. 71, pp. 315-323, 2014.

[13] S. F. Santos, D. Z. Fitiwi, M. Shafie-khah, A. W. Bizuayehu, C. M. Cabrita, and J. P. Catalão, "New Multi-Stage and Stochastic Mathematical Model for Maximizing RES Hosting Capacity—Part I: Problem Formulation," IEEE Trans. Sustain. Energy, Early access.

[14] S. F. Santos, D. Z. Fitiwi, M. Shafie-khah, A. W. Bizuayehu, C. M. Cabrita, and J. P. Catalão, "New Multi-Stage and Stochastic 
Mathematical Model for Maximizing RES Hosting Capacity—Part II: Numerical Results," IEEE Trans. Sustain. Energy, Early access.

[15] M. Alam, K. Muttaqi, and D. Sutanto, "Mitigation of rooftop solar PV impacts and evening peak support by managing available capacity of distributed energy storage systems," IEEE Trans. Power Syst., vol. 28, no. 4, pp. 3874-3884, 2013.

[16] K. Worthmann, C. M. Kellett, P. Braun, L. Grüne, and S. R. Weller, "Distributed and decentralized control of residential energy systems incorporating battery storage," IEEE Trans. Smart Grid, vol. 6, no. 4, pp. 1914-1923, 2015.

[17] G. Mokhtari, A. Ghosh, G. Nourbakhsh, and G. Ledwich, "Smart robust resources control in LV network to deal with voltage rise issue," IEEE Trans. Sustain. Energy, vol. 4, no. 4, pp. 1043-1050, 2013.

[18] Y. Wang, K. Tan, X. Peng, and P. So, "Coordinated Control of Distributed Energy-Storage Systems for Voltage Regulation in Distribution Networks," IEEE Trans. Power Del., vol. 31, no. 3, pp. 1132-1141, 2016.

[19] M. J. E. Alam, K. M. Muttaqi, and D. Sutanto, "Alleviation of neutralto-ground potential rise under unbalanced allocation of rooftop pv using distributed energy storage," IEEE Trans. Sustain. Energy, vol. 6, no. 3, pp. 889-898, 2015.

[20] M. J. E. Alam, K. M. Muttaqi, and D. Sutanto, "Community energy storage for neutral voltage rise mitigation in four-wire multigrounded LV feeders with unbalanced solar PV allocation," IEEE Trans. Smart Grid, vol. 6, no. 6, pp. 2845-2855, 2015.

[21] N. Jayasekara, M. A. Masoum, and P. J. Wolfs, "Optimal Operation of Distributed Energy Storage Systems to Improve Distribution Network
Load and Generation Hosting Capability," IEEE Trans. Sustain. Energy, vol. 7, no. 1, pp. 250-261, 2016.

[22] P. Hasanpor. Divshali and B. J. Choi, "Indirect Demand Side Management Program Under Real-Time Pricing in Smart Grids Using Oligopoly Market Model," presented at the The First International Conference on Green Communications, Computing and Technologies, France, 2016.

[23] M. J. E. Alam, K. M. Muttaqi, and D. Sutanto, "Effective utilization of available pev battery capacity for mitigation of solar PV impact and grid support with integrated V2G functionality," IEEE Trans. Smart Grid, vol. 7, no. 3, pp. 1562-1571, 2016.

[24] P. Hasanpor. Divshali, A. Alimardani, S. H. Hosseinian, and M. Abedi, "Decentralized cooperative control strategy of microsources for stabilizing autonomous VSC-based microgrids," IEEE transactions on power systems, vol. 27, no. 4, pp. 1949-1959, 2012.

[25] T. Ackermann. (2015, 2016-10-07). SNOOPI: Smart Network Control with Coordinated PV Infeed. Available: http://www.solarera.net/files/6614/5743/2451/049_Snoopi_Ackermann.pdf

[26] L. Hülsmann, "Evaluation of two distribution grids in terms of PV penetration limits and effectiveness of reactive power controls," Master of Science, 2016.

[27] B. Zakeri and S. Syri, "Electrical energy storage systems: A comparative life cycle cost analysis," Renewable and Sustainable Energy Reviews, vol. 42, no. 1, pp. 569-596, 2015. 